\title{
Physicochemical properties and bioactive compounds of selected seed oils.
}

\begin{abstract}
The physicochemical properties and chemical composition of oil extracted from five varieties of plant seeds (bittermelon, Kalahari melon, kenaf, pumpkin and roselle seeds) were examined by established methods. The thermal properties of extracted oils by differential scanning calorimetry were also evaluated. Sensorial profiles of these seed oils were defined through the CieLab $\left(\mathrm{L}^{*}, \mathrm{a}^{*}, \mathrm{~b}^{*}\right)$ colour. Most of the quality indices and fatty acid compositions showed significant $(\mathrm{P}<0.05)$ variations among the extracted oils. Physicochemical properties of the oils extracted were iodine value, 86.0-125.0 g I2/100 g oil; saponification value, $171.0-190.7 \mathrm{mg}$ of $\mathrm{KOH} / \mathrm{g}$ of oil; acid value, $1.1-12.9 \mathrm{mg}$ of $\mathrm{KOH} / \mathrm{g}$ of oil, free fatty acid, $0.6-6.5 \mathrm{~g} / 100 \mathrm{~g}$ of oil, and peroxide value $1.5-6.5 \mathrm{meq}$ of $\mathrm{O} 2 / \mathrm{kg}$ of oil. Palmitic, oleic and linoleic acids were the major fatty acids in all of the extracted seed oils except for bittermelon, where eleostearic acid was the major fatty acid. Gallic, protocatechuic, p-hydroxybenzoic, vanillic, caffeic, syringic, pcoumaric and ferulic acids were identified in the extracted plant oils. Among these, vanillic acid was predominant in all extracted oils. The oils were rich in tocopherols with g-tocopherol as the major components in all oil samples. Among the phytosterols, sitosterol was the major phytosterol extracted from the five plant seed oils. The seeds of these plants contain a great number of valuable minor compounds, which have a potential high value as food and for production of non-food products.
\end{abstract}

Keyword: Oil, Oilseeds, Physicochemical, Chemical composition, Thermal properties 